\title{
Research on the Impact of Big Data on the Development of Supply Chain Logistics Management
}

\author{
Xinchun Wang ${ }^{1}$, Dan Zhang ${ }^{1}$ \\ ${ }^{1}$ Chongqing Aerospace Polytechnic College, Jiangbei, 400021, Chongqing, China
}

\begin{abstract}
In the era of big data, information sharing functions are of great significance. Moreover, under the effect of big data technology, information sharing can also avoid the problems of traditional supply chain logistics management, develop personalized service content for users, and fully control order risks. This article summarizes the current situation of traditional supply chain logistics services based on previous work experience. The author discusses the impact of big data on supply chain logistics management from how to improve the effect of high-tech management and control, how to shift from price competition to value competition, how to build a "big logistics" system, reduce logistics costs, strengthen distribution efficiency, and improve the stability of the enterprise, how to enhance the user service experience these all six aspects.
\end{abstract}

\section{Introduction}

In general, supply chain management has obvious advantages in product quality maintenance, cost control, and shortening of order lead time. At this stage, many researches related to supply chain management mainly focus on applied value research. However, it can be seen from previous studies that problems such as information distortion or lagging are more common, which in turn triggers the "bullwhip effect", which has a great impact on supply chain theory. In addition, although many companies in traditional supply chain management are aware of the importance of supply chain management, due to the impact of information barriers, they cannot present the effect of real-time information sharing, which is also a problem that big data needs to solve.

\section{The Mechanism of Big Data-driven Supply Chain Logistics Service Upgrade}

\subsection{Big Data Drives Supply Chain Logistics Service Quality Upgrade}

The mechanism of big data-driven supply chain logistics service upgrade is shown in Figure 1. Throughout the supply chain and logistics operation process of an enterprise, a lot of data information will be generated. From the application of big data technology, basic data such as related products and rates within the enterprise have been fully used. In addition, driven by technological means, data sources are becoming more and more extensive, which can promote data sharing and cooperation to become more open, and the utilization rate of upstream and downstream cooperative enterprises and other external data has increased significantly. Relevant data research shows that about $57 \%$ of companies can master big data content such as storage and transportation of upstream and downstream cooperative enterprises, and $39 \%$ of companies can master big data content provided by external agencies. Due to the relatively complex data, companies need to make relevant analysis results more scientific with the help of demand forecasting, management decision-making and other content, and ultimately achieve a comprehensive upgrade of the quality of supply chain logistics services [1].

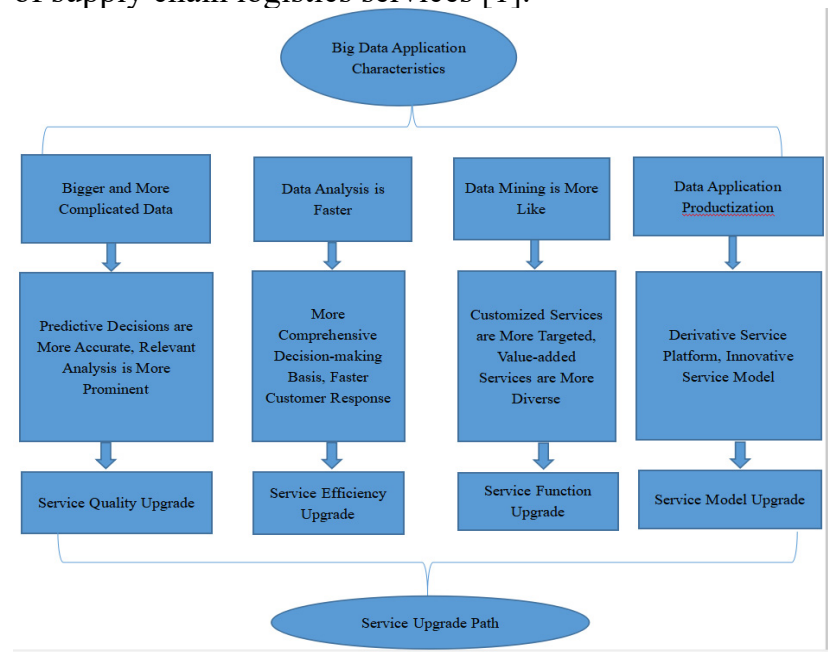

Fig1. Big Data Drives the Driving Mechanism of Supply Chain Logistics Service Upgrade

\subsection{Big Data Drives the Efficiency Upgrade of Supply Chain Logistics Services}

With the help of big data technology, data processing speed is gradually increasing, which can help companies consider various influencing factors in a short time. 
Related research shows that more than $60 \%$ of companies have applied big data to optimize picking routes and automatic replenishment. If it is under traditional analysis technology, it is difficult to quickly complete decisionmaking operations. It can also be seen from this that big data technology can make decision-making basis more comprehensive and ensure the comprehensive upgrade of supply chain logistics services.

\subsection{Big Data Drives the Upgrade of Supply Chain Logistics Service Functions}

In the era of big data, data mining technology has been steadily updated. This can ensure that a more specific and targeted analysis operation is carried out based on the original data preprocessing. For example, staff can use marketing data to perform customer portrait operations and develop corresponding customized services. In terms of distribution data mining, big data can optimize distribution routes and do a good job in the integration of distribution resources. Besides, it can also provide users and subcontractors with value-added services such as model selection, and help companies expand the supply chain logistics service chain. This is also a necessary condition for the transformation and upgrading of such enterprises.

\section{Current Status of Traditional Supply Chain Logistics Services}

\subsection{High Inventory Levels and High Operating Costs}

In order to avoid out-of-stock issues and optimize users' purchasing experience, people need to find a balance between transportation and warehousing costs among various nodes in the supply chain, and determine recurrent inventory content. Meanwhile, in order to reduce the probability of related problems, companies need to appropriately establish a safety stock based on recurrent inventory. When the inventory in the warehouse is below a certain standard value, the time to order will appear. In the past development, companies generally adopted the "inventory for inventory" approach. Affected by the "bullwhip effect", the demand for the entire supply chain is expanded, which makes the overall inventory of the supply chain moderately high. In the meantime, there are obvious problems such as distortion and lag in the transmission of information. The upper and lower node enterprises and the various supply chain links are not perfect, and they cannot truly achieve an orderly connection, which increases the operating cost of the supply chain [2].

\subsection{Poor Delivery on Time}

With the intensification of market competition and the development of economic globalization, consumers are more willing to pursue personalized products, and to ensure low prices, good quality, and faster update speeds, making "time" an important factor in strengthening the competitiveness of the entire supply chain. In actual development, supply chain enterprises should respond quickly, deliver on time, shorten the order period, and ensure that the supply chain can operate agile and efficiently. But because the information cannot be seamlessly connected, it is difficult to deliver on time. Even if "just-in-time" procurement and production are achieved in the work, the result is only the transfer of inventory from one supply chain node to another supply chain node. It can also be seen from this that in order to achieve punctuality, the cost of "high inventory" is required.

\subsection{The Quality of Logistics Services is Difficult to Guarantee}

In terms of overall product quality presentation, in addition to the quality of parts and intermediate products, it is also directly related to the quality of logistics in the flow process. In fact, some qualified products will be lost in logistics. For this reason, people need to use the supply chain to realize the supervision of the entire logistics process, avoid the impact of logistics service quality, and eliminate inventory problems. More importantly, there are obvious limitations in the information content. This will cause the supply chain logistics to fail to play a role, and it is difficult to ensure that the supply chain is operating efficiently.

\subsection{Integrated Supply Chain Logistics is Difficult to Achieve}

Nowadays, with the increasing pressure of market competition, it is difficult for a company or a product to gain an advantage in the market. For this reason, in the actual supply chain design, each enterprise should establish an effective cooperative relationship, strengthen its own competitiveness, and achieve integrated management of the supply chain. Otherwise, supply chain management can also create favorable conditions for subsequent logistics system design, ensure the effective connection of various links, and win more business content for the enterprise. But from the perspective of specific work, the actual supply chain logistics construction also has certain prerequisites, that is, the seamless sharing of information. However, there are always various problems in information sharing, which ultimately leads to the failure of the integrated supply chain logistics to be fully implemented [3].

\section{The Impact of Big Data on Supply Chain Logistics Management}

\subsection{Improve the Effect of High-tech Management and Control}

At this stage, the application of big data technology is mainly based on the development of the Internet, and a series of cloud data is generated by connecting basic things in various industries. This can ensure that the accurate calculation of each link can not only maintain the logistics efficiency without any impact, but also control the logistics cost while achieving precise control. For example, in the 
development of cold chain logistics, the transportation temperature is higher than other logistics requirements. It mainly includes several large temperature zones, and the control requirements of different temperature zones are different. What'smore, China's current cold chain transportation companies cannot achieve full cold chain transportation in order to control costs. This has a great impact on the quality of fresh products, and the effect of user consumption experience will also be greatly reduced. But after the Internet of Things era, cold chain logistics can use big data, information technology, etc. to give cold chain logistics more intelligent features to strengthen the efficiency and quality of cold chain distribution. This can also ensure the overall management and control of the entire cold chain process. Furthermore, big data can make targeted stocking after clarifying regional consumption trends by drawing shopping maps. This can not only avoid a large inventory backlog, but also reduce logistics and transportation costs.

\subsection{From Price Competition to Value Competition}

As online platforms become more and more perfect, China's e-commerce has substantially improved, but the overall logistics demand is also increasing. The expansion of market share has brought more development opportunities for various logistics express companies, but it has also increased the pressure of competition among the logistics industry. Enterprises who want to obtain higher market share and economic benefits should rely on their own advantages to compete for favorable value. After that, enterprises need to change the previous form of competition by strengthening their own service quality, so as to create more favorable conditions for their own development. Enterprises also need to adopt big data technology and cloud computing technology to comprehensively process logistics data. This is also the process of optimizing the allocation of own resources, which can truly complete the effective creation of selfworth [4].

\subsection{Build A "Big Logistics" System}

In the process of application and promotion of big data technology, the big logistics system has gradually been applied, which has prompted an important turning point in the development of the entire logistics industry. The large logistics system mentioned here mainly refers to the coordination of the enterprise's own logistics resources and the resources of third-party logistics enterprises to ensure that resources can be used more efficiently and stably. This is also the essence of controlling logistics costs. After the completion of the construction of the large logistics system, enterprises can better establish cooperative relations with professional logistics companies. Enterprises can obtain more support from third-party logistics companies according to their own needs, making their own commodity transportation simpler and more efficient, while ensuring their own economic benefits, while achieving mutual benefit with third-party logistics companies, and truly achieving common development. For example, in the truck help logistics information interconnection platform, there are more than 5 million pieces of information about the source of goods every day, and the transaction amount exceeds 1.7 billion yuan. This will generate a lot of logistics data, which is also a prerequisite for the construction of the "big logistics" system.

\subsection{Reduce Logistics Costs and Strengthen Distribution Efficiency}

After the continuous development and improvement of big data technology, many high-tech technologies such as big data storage technology and big data management technology will be applied in logistics, transportation and management. These technologies can well realize the collection and identification of information in the logistics management and transportation process, and achieve the rapid dissemination and application of information, which can create favorable conditions for the data application in the logistics process. It is precisely because of the continuous improvement and development of big data technology that many companies have formed a comprehensive management of their own logistics operations centered on their own data. Simultaneously, companies can better manage related staff and determine the best logistics transportation and distribution plan. This can not only strengthen its own logistics efficiency, but also reduce many costs incurred in the logistics process.

\subsection{Improve the Stability of All Aspects of the Enterprise}

Looking at the application of big data technology in the logistics management process. It is no longer limited to a single logistics data processing. It plays an important role in the actual logistics warehousing and transportation, postsales and distribution processes. At this stage, logistics big data has covered the entire logistics management industry chain process, and it has become an important support for enterprise logistics management and logistics decisionmaking. For example, Amazon has developed a new patented technology in recent years, which can help companies carry out predictive transportation operations. With the help of this technology, online retailers in various regions can have a comprehensive understanding of consumer spending habits in various regions. It can clarify their personal shopping needs according to users' search frequency and browsing time, etc., and then make orderly adjustments to their own goods inventory, formulate a more targeted sales plan, and better achieve product sales and transportation. In general, the continuous development of big data technology can make smart logistics more perfect and make all logistics links in a unified state. This can reduce the logistics costs in each link. In addition, with the help of Internet technology, the comprehensive production and circulation of commodities can be realized, and the enterprise is in a state of comprehensive development [5]. 


\subsection{Strengthen User Service Experience}

In the process of application, big data technology can not only provide new methods for enterprise logistics transportation and distribution, but also improve management procedures for specific logistics management links. It can even make accurate predictions to meet the consumer needs of different regions and different users, predict consumer behavior, and provide assistance for enterprise development. Besides, with the help of big data technology, staff can understand end-to-end browsing, shopping, and delivery records. Through the comprehensive mining and analysis of data and the full use of these analysis results, each logistics enterprise can provide users with comprehensive services. Simultaneously. In this way, it can also deal with commodity transportation and distribution issues more accurately, and communicate better with customers. More importantly, companies can also provide users with good customized service tools to optimize their service experience and generate greater recognition for the company. This also has a positive effect on the subsequent development of the enterprise.

\section{The Future Development Trend of Supply Chain Logistics Under Big Data}

\subsection{Lean Management, Quick Response}

From an essential point of view, the implementation of lean management is mainly to ensure the integrity of supply logistics management. At this stage, due to the intensification of market competition, users appear to be more critical and individual, resulting in some "loving the new and disgusting the old". Each supply chain enterprise should sort out the supply chain at this stage according to the actual situation, truly achieve lean management, and reduce the probability of waste. Managers also need to provide comprehensive guarantee for the follow-up supply chain logistics development according to market demand. Only in this way can we ensure the maximization of enterprise development benefits.

\subsection{Shared Logistics, One-stop Service}

At this stage, the sharing economy has been applied in many fields, especially in the logistics industry, where its application value is more obvious. For example, "shared warehouse" and "shared capacity" have created many favorable conditions for the development of cross-border e-commerce. Besides, companies can also rely on technologies such as the Internet and cloud computing to ensure that the supply chain can integrate and share highquality global logistics resources. Enterprises also need to actively respond to the call of the state, so that upstream and downstream enterprises in the supply chain can always maintain interconnection and achieve one-stop service. The application of new technologies can not only reduce the logistics cost of the supply chain, but also make the overall logistics fee service more complete. From the perspective of supply chain nodes, managers need to focus more on production and operations. At the same time, various companies need to establish cooperative relations to strengthen product competitiveness [6].

\subsection{Real-time Accurate and Efficient Matching}

The application of big data technology can connect suppliers, wholesalers and other users together to establish a complete "shared logistics big data platform". The actual supply chain logistics provider can know the sales and consumption of member companies at any time. In some special circumstances, logistics service providers can use big data platforms to better understand user needs. Meanwhile, the big data platform can also implement the best matching logistics resources, and do a good job in the comprehensive docking operation of upstream and downstream enterprises in the supply chain. The big data platform can also establish in-depth cooperation with supply chain companies offline, which can provide more efficient logistics services through real-time tracking. It is also with the help of the above operations that companies can provide users with a better experience.

\subsection{Integrated Development of Informatization, Greening and Intelligence}

The actual implementation of supply chain management is mainly based on the basic concept of "eliminating all waste". Otherwise, the implementation of supply chain management in a big data environment can better lift information barriers, make real-time information sharing possible, and establish a green supply chain mechanism. This is also a necessary condition for the green development of logistics. Each node enterprise must also match each other, seamlessly connect, and accurately control user needs, which is synchronized with the green concept. "Big data + supply chain" construction can make the green construction of logistics management smoother and transform the existing supply chain logistics system. Establishing "big data + smart logistics" to integrate specific logistics resources and clarify changes in market demand can bring more new opportunities for enterprise development.

\section{Conclusion}

In summary, many companies have already begun to implement information construction operations in production management. With the continuous improvement of the level of informatization, the application of big data technology in enterprise logistics management has become more frequent. People can build a data center with the help of big data technology, dig out the hidden value of the data, and strengthen the development benefits of logistics enterprises. To this end, managers should focus on the use of big data advantages to ensure the integrity of their own strategic development plans. 


\section{References}

1. Zhang Xiao. The impact of big data on the development of supply chain logistics management [J]. China Business Review, 2020(24): 47-48.

2. Zhou Shuo. Research on "Big Data" Promoting Supply Chain Logistics Service Upgrade[J]. Fortune Today (China Intellectual Property), 2019(10): 25.

3. Liu Yanjiao, Zhu Tiangao, Gong Yunfeng. Analysis of the impact of big data on the development of supply chain logistics management[J]. Market Modernization, 2019(16): 65-66.

4. Fan Xingbing. Research on Customer Relationship Management of Third-Party Supply Chain Logistics Enterprises Based on Big Data_-Taking Anhui CJ Supply Chain Logistics Co., Ltd. as an Example [J]. Journal of Jishou University (Social Sciences Edition), 2019, 40(S1) ): 126-128.

5. Ma Jie. Research on the Upgrade Path of Supply Chain Logistics Services Driven by Big Data[J]. Business Economics Research, 2019(11):105-107.

6. Ma Jie, Zheng Caiyun. Application of big data for supply chain logistics service upgrade status and demand analysis [J]. China Business Forum, 2019 (04): 12-13. 